\title{
Turpin's Cave: choice and deception in a virtual realm
}

\author{
Dr Eleanor Dare
}

School of Communication, Royal College of Art, London, United Kingdom

eleanor.dare@rca.ac.uk,

Royal College of Art, Garden House, Dorando Close, London, W12 7TU

Telephone: +44 (0)20 75904314

Dr Eleanor Dare is the acting Head of Programme for the MA Digital Direction at the Royal College of Art, London, her work is concerned with art, computation and the limits of symbolic logic.

\section{Turpin's Cave: choice and deception in a virtual realm}

The VR work Turpin's Cave (2018) began as an account of the author's childhood memories of a chimeric cave in Bostall Woods, South East London. That part of London is subject to dramatic sink holes and subsidence, which in this work are a metaphor for unreliable memory, but also, as the project unfolded, became a potent symbol for the increasingly precarious nature of contemporary employment. In creating this project, the author found herself engaging with a gig economy of actors operating within a creative precariat, in which the 'choice' and 'flexibility' of deregulated work arguably creates a veneer of individual freedom. Through this project the author seeks to deconstruct some of the rhetoric of empathy, choice and immersivity that has grown around VR, evaluating whether the ontological instability of the form has non-trivial connections to the increasing precarity of global employment (Walls et al, 2016). 
Keywords: virtual reality, memory, choice,

Subject classification codes: include these here if the journal requires them

\section{Introduction}

'I've lived here all my life, but I've never heard of a cave' (woman in Bostall Woods,

Image 1. 360 footage of Bostall Woods, possible site of the missing cave.

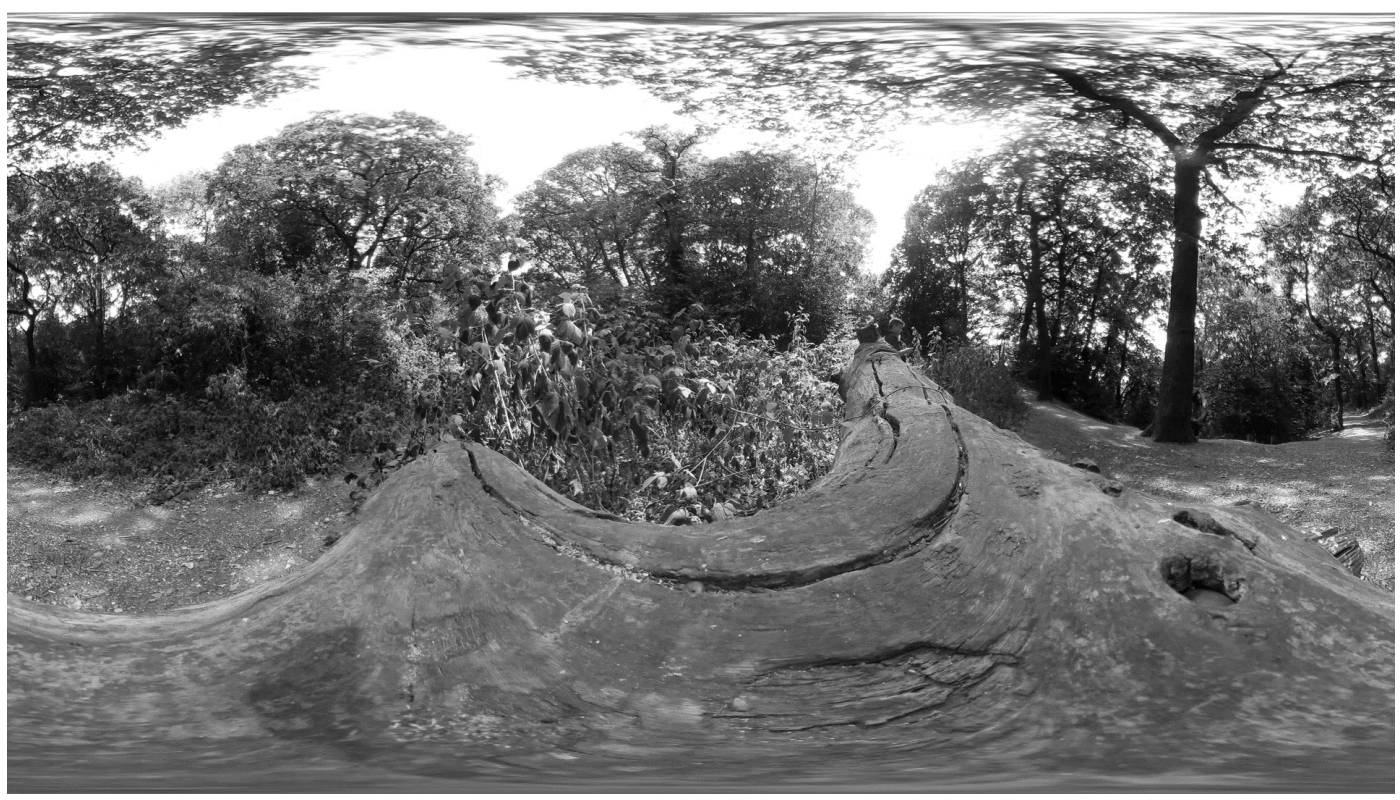

Turpin's Cave is a location based Virtual Reality (VR) creative non-fiction work,

designed to be performed in a specific cave in South East London. As a child in the 1970s, I vividly remember seeing the cave entrance while accompanied by my mother.

The cave entrance I remember was green with moss, small, dank and richly dark, barred like a prison, to prevent children from disappearing into it. Unfortunately, despite repeated recent visits to the location and detailed questioning of locals, and my mother, I am yet to locate the cave of my memories. My only access to the idea of the cave is through the images in my mind's eye, as well as my 3D simulations and online research, which, so far, suggests the cave(s) did exist at some point. Maps of the area indicate a 'Turpin's Cave' at the South Western edge of Bostall Woods. 
The project began, in an orthodox fashion, as an account of my childhood memories of a chimeric cave in Bostall Woods, South East London. My memories of childhood are largely fragmented and blurred, making this recollection a potent one, by dint of its exceptional clarity and the presence of my mother, of whom I have very few childhood memories. That part of London is subject to sinkholes and subsidence, which in this work have become a metaphor for unreliable memory and loss, but also, as the project unfolded, an exploration of the precarious nature of much contemporary employment. We live in an era in which 'more professionals face the prospect of a contingent lifestyle of informal, on-demand work, the loss of temporal stability' (Gregg, 2018); my encounters with jobbing actors reinforced the theme of precarity over several months.

In staging and developing the work, and in particular, commissioning actors, the piece evolved into a non-fiction drama with an alternative set of narratives, addressing the contingency and insecurity of contemporary employment practices, summed up by Guy Standing's term, the 'Precariat' (2011), meaning people trapped long-term in precarious employment - often on 'zero-hours' contracts, with no pension, no housing security, no savings and minimal employment rights.

'the precariat could be described as a neologism that combines an adjective 'precarious' and a related noun 'proletariat'.....We may claim that the precariat is a class-in-the-making, if not yet a class-for-itself, in the Marxian sense of that term.' (Standing, 7). A significant aspect of the Precariate is a lack of representation security whether through unions or legal representation, the lack of a 'collective voice in the labour market, through, for example, independent trade unions, with a right to strike' (11). My assertion is that insecure temporary employment has an ontological relationship to a disorienting virtuality, that both phenomena are representationally unstable, symptomatic of our contemporary condition, belying 'the rhetoric of the media 
industry and .....how it would like to define itself.' (Zahlten, 2017). Constructs such as the 'Empathy Machine' (Milk, 2015) and 'worker flexibility' (as associated with Zero Hours contracts) (Taylor, 2018) are symptomatic of the same neo-liberal, technologically determinist trope.

In Open Sky (1977) Virilio predicted the tensions between an implosion of digital interactivity and globalized digital labour: 'The conjunctive proximity of continental development is today superseded by the disjunctive precariousness of worldwide time-management practices that provoke a sort of disintegration in the sociopolitical organization we have inherited from past centuries (Virilio, 1977, 86). It is this very disintegration which, in Turpin's Cave becomes a teleologic rupture. Before elaborating on the significance of the Precariate and its destabilizing relationship with (digital) empathy rhetoric, I will explain how Turpin's Cave currently unfolds for its viewers, albeit, that until the cave is discovered, those viewers can experience only a virtual version of the virtual reality I envisage; what they encounter is no more than a set of flickering shadows on the walls of a cave I have not been able to locate in the real world.

\section{Materials and methods}

Turpin's Cave is intended for adult audiences, the VR experience lasts for about 12 minutes. The narrative begins inside a VR headset, in the dark. If you were experiencing the location-based performance, this is what would happen: you would see the entrance to two passageways, two possible tunnels, each time you looked at the passages a different voice would speak. Looking towards the passage on the right would trigger the voice of a young South Asian man, Dev; he would start to speak, his voice would be 
warm and calm, with a hint of the metallic, as if he was talking from inside a tin box:

Hair: mourning black, an absorption of all association. Light absent. No touch, no smell. No images bedded down in the neuron trails. Above all features your hair eludes me.

If you looked the other way, towards the other passage, his voice would abruptly stop and another voice would begin to recite the same words, an actress called 'Mavis' would speak, her voice would have a Northern inflection, it would be a bit harsher than Dev's voice, slower and more actorly. Throughout this experience, depending on which voices your attention favoured, a different set of voices and processes would unfold, with subtly different shifts in spatial surroundings, from a large room to a 'realistic' cave, to a cave 'skinned' in textures evoking historical cave games, such as Spelunky (Yu, 2008) and Colossal Cave Adventure (Crowther, 1976).

My intention is to locate the cave I remember from childhood and stage the VR drama in front of it, in the depths of Bostall Woods. In the speculative performance a single audience member would wear a headset, starting with the actors standing beside them, at each side of the cave entrance. Depending on which side the headset wearer looks, one of the two actors will narrate the same text. Inside the headset the cave will be visible, with two possible passageways beckoning them to step inside it, as if there were no bars. As the performance progresses the wearer would move deeper into the cave, the passage will be determined by their bias towards one of two initial actors. Half way through the performance recorded voice-overs of other actors would replace Dev and Mavis's live voices.

At the centre of the cave the wearer will hear about the history of the missing caves, that they were part of a nineteenth century chalk mine, covered over to save children from danger. The idea of the cave's association with the highway Robber Dick Turpin would 
be dashed, instead, the wearer would be offered one of two closing routes, represented by two voices, which, the wearer is then informed, cost $£ 5$ per 100 words.

The risible pay and conditions of the actors, combined with the notion of user choice are presented in the putative finale as provocations, challenges to the idea of 'choice' so deeply embedded in the language of advertisers and the digital business ontology.

\section{Evaluating Turpin's Cave}

The cave at the heart of this narrative has not been located yet, Turpins' Cave therefore remains a virtual work, consisting of a VR application and supporting materials. The project has been presented at conferences, at symposia and in teaching situations. The VR app and images of my journeys through Bostall Woods are the focus of user evaluations in the form of conversations, as well as feedback on the written narrative (meta narrative) about my attempts to locate the cave. I was reluctant to ask respondents if they found the work 'immersive', as I have critiqued this term vocally, but I did ask if it was engaging, something they wanted to see through to its end. One person told me: 'Yes, it takes you with the voices, but then it confronts you with the conditions of its making.'

Many people continue to be shocked that I wish to critique empathy, including, in my experience, a sizeable number of MA students, but also successful VR documentary film producers. I am left with the impression that the construct of empathy is sacrosanct to many people, that for them, it is taboo to critique it.

Another subject told me: 'The voices in the story are the tools.'

I asked them if the word 'tools' implied an exploitative scenario, they replied they didn't necessarily mean that, but the voices were something I had purchased. I asked if 
that was any different from other scenarios with actors? 'No', they replied, adding: 'The project is about temporal instability - you are linking the VR form to the way those actors and other people earn their living - everything is unstable.'

My conclusion is that the work does provoke its audiences, but whether such provocation is generative of non-trivial agency or political change is still open to question, my main goal is to expand discourse about the nature of VR and its relationship to wider digital discourse and practices, as discussed in the next section.

Image 2. Scene from Turpin's Cave, with texture referencing historic cave games, such as Spelunky (Yu, 2008) and Colossal Cave Adventure (Crowther, 1976).

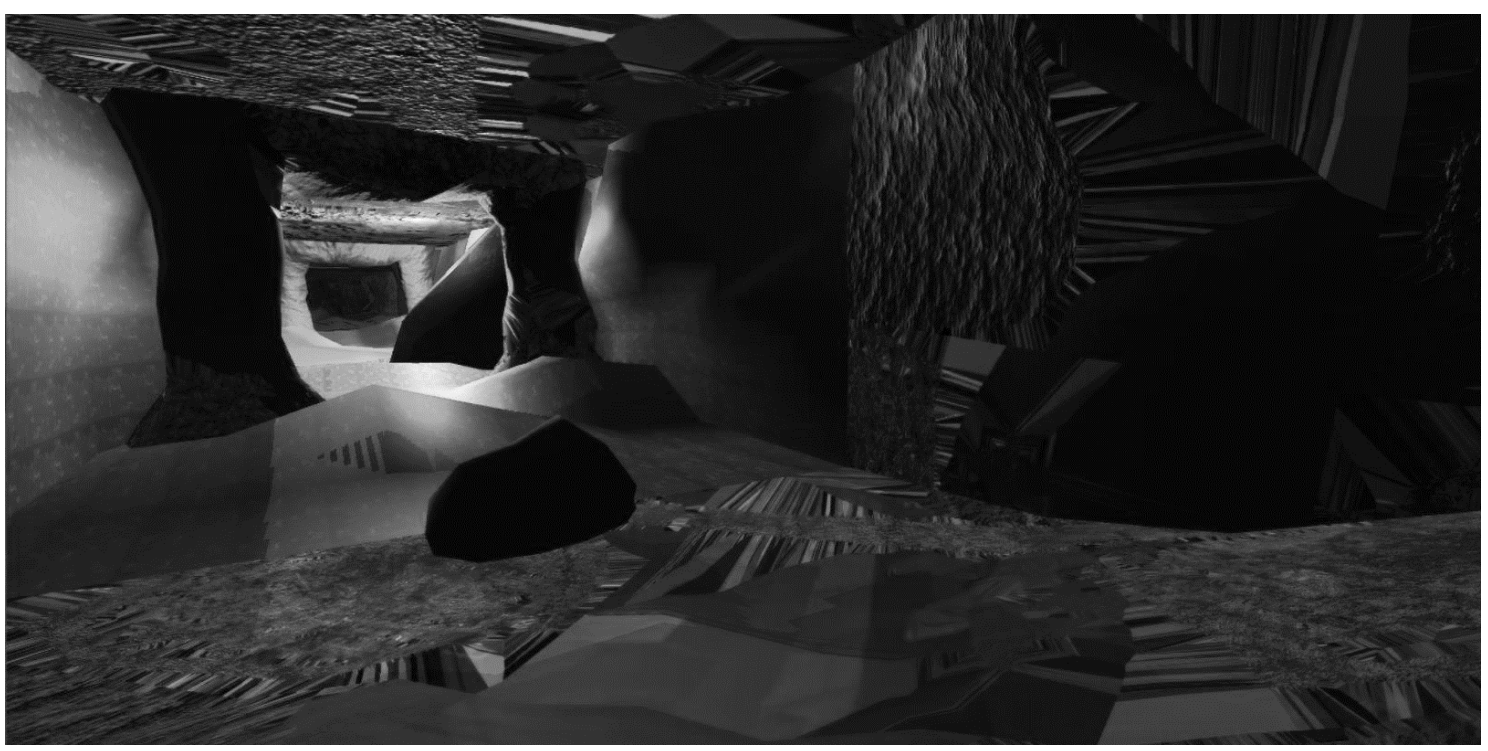

Image 3, Scene from Turpin's Cave, with texture referencing historic cave games, such as Spelunky (Yu, 2008) and Colossal Cave Adventure (Crowther, 1976). 


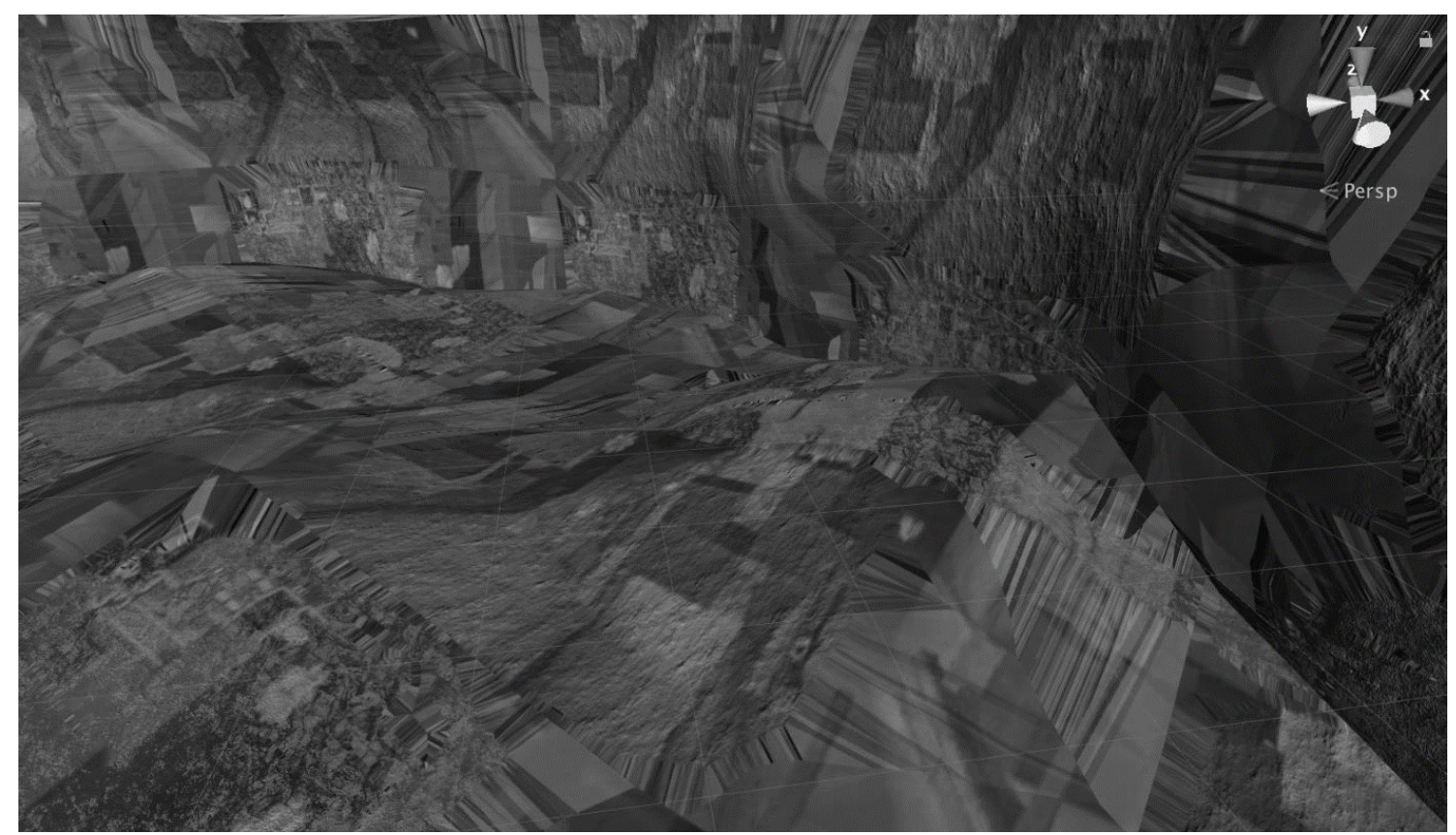

Image 4, scene from Turpin's Cave, looking to the left or right triggers different voicings of the narrative.

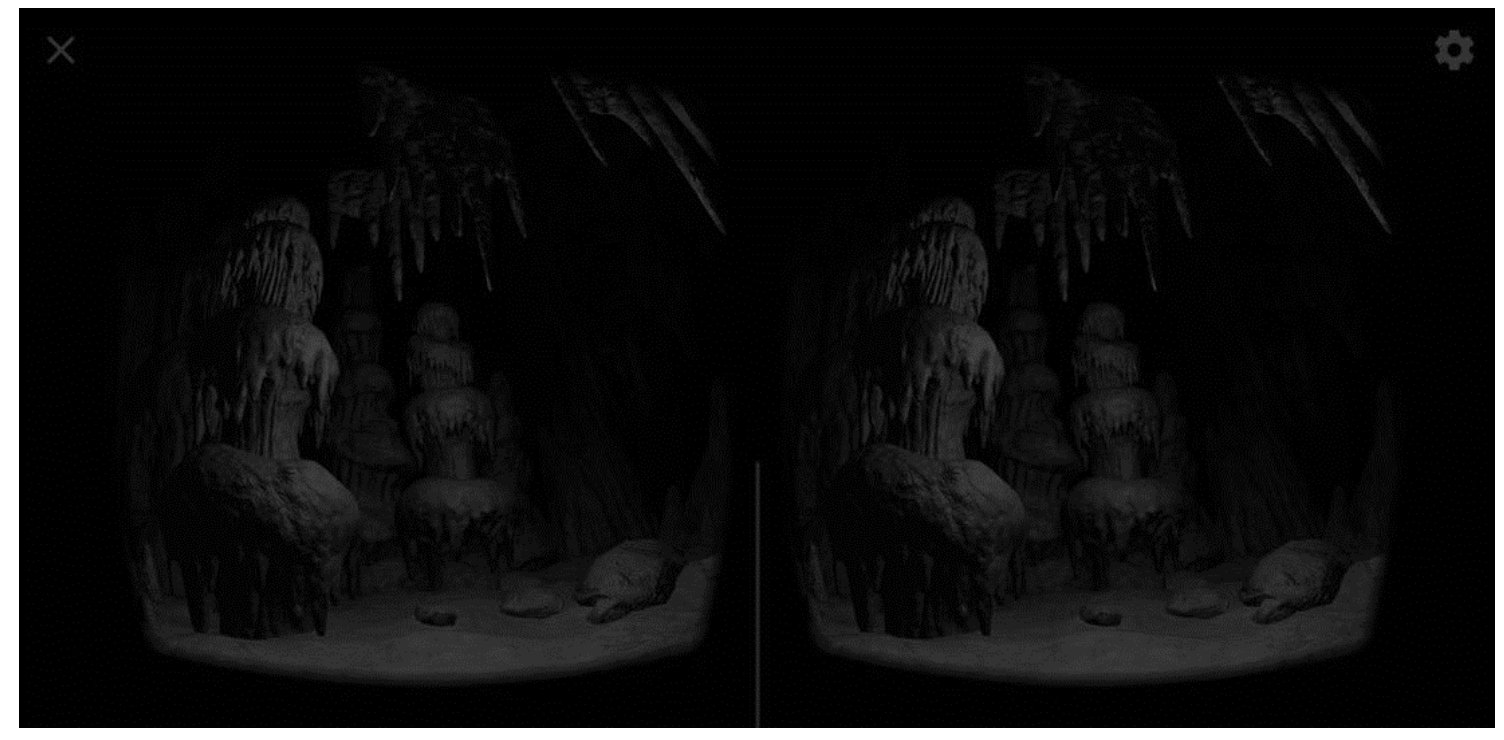

\section{Discussion}

Much has been made of VR's immersivity and apparent ability to generate empathy.

Rose points out that the association between VR and empathy is currently 'ubiquitous in conversation and in literature at industry events where VR nonfiction is shown. An 
online search on VR and empathy (as of June 2017) yields thousands of results-many uncritically repeating the claim to a link between the platform and this particular affective response' (Rose, 2015)

There is also great investment in the possibilities of immersive and interactive media to boost the UK economy, evidenced by multi-million pound government initiatives such as the $£ 33$ million UK Research and Innovation 'Audience of the Future Challenge,' which confidently asserts: 'The best storytellers use the most exciting technology available to capture our imagination' (ukri, n.d), but there are also longstanding fears, for example, 'that digital technologies are leading film into a descending spiral of spectacular superficiality' (Dovey et al, 2003, 137). Such fears are evident in both popular film criticism and academic discourse.

Fifteen years ago, Dovey et al wrote that even 'VR's status as a single technology is suspect. As Hillis asks, does anything set VR apart from 'TV and telephony from which it is partly cobbled, imagined and extended?' (Dovey et al 2003:70). Suchman (2016), Halpern (2015) and Rose (2018) have followed up with critiques of the form's overdetermination, its close association with military simulation, but a critical mass of writing which challenges the most prevalent platitudes of VR still seems absent. It seems also, that the concept of immersivity and presence is entwined with a notion of empathy, 'major views of empathy split between the sharing of feelings between people, or what is often referred to as emotional empathy, or the imagining of being in another's place'(Segal et al, 2017). It is difficult to disentangle these three pillars of VR ideology, in some ways it risks being taboo to question either. Pedwell, writes that: 'empathy is now everywhere and is viewed, by definition, as positive. Understood in shorthand as the ability to 'put oneself in the other's shoes', empathy is, 
according to these narratives, what 'we' want to cultivate in ourselves and others. It is the affective attribute that we want to define 'our' society' (Pedwell, 2012: 280)

But empathy is predicated on a neo-liberal reduction to the individual as the agent of change, it is frequently positioned as if immune to negative bias, as if innately beneficent, a category of knowing that is ethically superior to 'rationality' or 'reason': 'Empathy is the stepping stone to tolerance and well-being, the bedrock to any strong community,' (Project Empathy, n.d) states the Project Empathy landing page, but empathy is a model of moral agency which cannot account for systems or systemic processes, nor can it help us identify our own biases in feeling - who we do and do not feel for.

Paul Bloom's idealization of Western rationality, in Against Empathy (2017), is arguably no less reductionist, but is still valuable for being a rare critique of neoliberal empathy rhetoric. Other papers, while extolling empathy, acknowledge its limitations: 'Several factors moderate and even completely block empathic responses. These include psychological processes that preempt empathy, for example perceptions of unfairness (Decety and Cowell, 2015) and dehumanization-associating others as machines, nonhuman animals or as individuals with no human rights (Bain et al., 2013).' (Bertrand et al , 2018).

In the last six years the rhetoric of empathy, often expressed as the ability to 'walk in others shoes,' has reached a saturation point, in which, for example, at a recent UK NCCPE engagement training event, every project generated during the training exercises invoked empathy as its output and implied teleology.

'Precisely because it is so widely and unquestioningly viewed as 'good', its naming can represent a conceptual stoppage in conversation or analysis' (Pedwell, 2012: 281). And yet there is so much invisible, uncredited work and dehumanizing 
deregulation hidden within the supposedly empathetic form of digital media. The actors in Turpin's Cave were sourced from an online platform (one of many) which offers the labour of voice-over artists, 3D modelers, Photo and film editors, VR developers and other digital workers, on a piece-work basis. There are no permanent contracts, no annual leave entitlements or maternity/paternity pay, no sick leave or pension; it is a version of Uber or Just Eat for creative practitioners. These sites represent Platform Capitalism in the service of techno-rhetoric around the democratisation of digital technologies, a zero-empathy economy of techno-serfs.

The actors in Turpin's Cave were paid $£ 5$ for voicing and recording 100 words, a service that I became aware of when some of my own students started using it, but, of course, upon further investigation, it is obvious that this is a platform which, above all, overs it workers precarity. I take no pride in this uncomfortable knowledge of having participated in the exploitation of my fellow 'creatives,' having worked on academic zero-hours contracts for four years between 2012 and 2016, I can indeed verify the demoralizing and hopeless nature of risible pay and conditions, at no point was the rhetoric of flexibility and choice a reality for me. Perhaps unsurprisingly, empathy and economic-reality do not seem to collide at a wholistic level in VR any more than in the non-virtual realm.

In contrast to works which overtly seek to generate 'empathy', such as Jane 'Gauntlett's In My Shoes, (2015), a work, whose power arguably lies, not in its evocation of empathy, but in the excellent writing and intriguing sarcasm of the epileptic protagonist, it is described as:

'an internationally recognised empathy project, it is an ever-expanding collection of first-person documentary style interactive performances, which guide participants through the beautiful, the challenging, the mundane and the surreal aspects of being 
human.......Dancing with Myself dares you to let go of your preconceptions and step into Jane's shoes for only 20 minutes. It is her story, told through her eyes, and with her thoughts - faithfully recreated in an immersive, empathetic, and theatrical experience.....' (Gauntlett, n.d).

At the other end of the empathy spectrum, Langlands's and Bell's, The House of Osama bin Laden, (2003) was an interactive installation which digitally recreates the house in Afghanistan once inhabited by Osama bin Laden. The discursive nature of Langlands and Bells interactive work enables a critical exploration of the West's intervention in Afghanistan. The work deliberately evokes computer games, allowing users (or visitors) to explore the rooms using a joystick, so that they can:

manipulate the images projected before them. You will be able to wander around the promontory near the town of Daruntah where it was built and look out over the nearby reservoir to the mountains beyond, as bin Laden must have done many times until the presence of American operatives in nearby Peshawar forced him to decamp to the safer, less isolated environs of Kandahar. You will be able to see the small mosque made for his personal use, and examine his bunker built from used ammunition boxes filled with stones, its ceiling beams made from the chassis of an old Russian army truck. As art installations go, this is a ghostly and disturbing one, made all the more surreal by being created from the same software utilised by the computer game Quake (O’Hagan, 2003).

The work is arguably an inversion and subversion of 'heritage' culture, and of empathy rhetoric; there is no immersive gift shop or tea room, there are no Osama Bin Laden tea towels available here, if there is empathy it is subsumed by curiosity and the vicarious pleasure of reality TV. The work evokes something closer to the fly-on-the-wall documentary, or the scopophilia of 'gray tourism', this is not empathy as we know it through its habitual idealization. More recent works such as 'Clouds over Sidra' (Arora \& Milk, 2015) famously invoke the rhetoric of empathy, Chris Milk, in his Ted Talk stated: 'So, it's a machine....but through this machine we become more compassionate, we become more empathetic, and we become more connected. And ultimately, we become more human.' (Milk, 2015). 


\section{Conclusion}

My work with VR aims to test the limits of its ontology. The work also draws upon our collective heritage of games and stories which deploy caves, a heritage which goes back to the earliest days of computer games and VR technology. My aim is to test the limits of these VR associated qualities: Empathy, Immersion and Presence.

Mestre defines immersion in a virtual environment as: 'capable of producing a sensation of Presence, the sensation of being there (part of the Virtual Environment).' (Mestre, 2005). Presence is indeed, historically, at the core of VR and has often been cited as 'a sign of the "ecological validity" of VR devices.' (Mestre, 2005). The pleasures and anxieties projected upon the concept of the virtual, seem very familiar. Aristotle (330 BCE) saw the virtual as a potential refuge from the everyday, a place of intellectual freedom, which enables us to confront the real, while Plato (360 BCE), saw dangers in the escapism of the virtual, his metaphor of the cave suggests we might lose touch with reality if we embrace the virtual realm too readily.

In a more nuanced vein, Katherine Hayles, defines 'virtuality' as it exists pervasively in digital culture, as the "perception that material objects are interpenetrated by information patterns' (Hayles, 1999: 13). In which, 'as we move around our physical environments we encounter and engage with the products of computed information at every turn' (Dovey et al, 125) According to Dovey et al: 'Virtual reality is frequently seen as part of a teleology of the cinema - a progressive technological fulfilment of the cinema's illusionistic power' $(133,2003)$. 
Given the pervasive attempt to create different forms of immersion, including the non-figurative architectural spaces of historical Islam and Judaism, it is a good idea to ask ourselves about the precise nature of our own experiences, to see if we are really taking about a specific digital technology, or a wider range of mediated practices.

Marie-Laure Ryan's (2015) work calls for a phenomenology that analyses 'the sense of "presence" through which the user feels corporeally connected to the virtual world' (2001: 14). Again, VR might promise a shift in emphasis which many philosophers, artists and interaction designers are engaged by. A key question for us all to think about is this: Does the embodied nature of VR change our relationship to the image? Does the real disappear with VR or is it re-established? Re-grounded?

Humans have probably experienced 'immersion' and 'presence' for millennia, one only has to enter a cave or a cathedral to experience such a phenomenon. It is not hard to imagine that humans have thought about what it means to create new worlds with technologies such as sculpture and painting, photography and the moving image for as longs as they have existed. But it is important to pay attention to what Grau (2004) has written about acknowledging the specificity of virtual art:

'Integration of virtual reality into the history of immersion in art must not lead to disregard of the specific characteristics of virtual computer art' (Grau, 2005, 7). Grau also asks us 'whether there is still any place for distanced, critical reflection - a hallmark of the modern era - in illusion spaces experienced through interaction' (Grau, 2004,10 ), does the 'invisibility' of the VR interface reduce our ability to maintain critical insight? Turpin's Cave is an invitation to test the extent to which VR can support critical distance while inviting a degree of 'immersion' (or suspension of disbelief) which is arguably vital for engaging audiences. However, my argument is that ‘choice', ‘empathy'. 'immersion' and 'presence' are symptomatic of both VR's over 
determination as a technology and its uncomfortable entanglement with the language of advertising.

As Sismondo $(2010,5)$ reminds us: 'Technologies are political, because they enable and constrain action', they also risk reinforcing 'existing power structures' (Sismondo, 2010, 73). One of the strengths of both Science and Technology Studies (STS) and a feminist STS, is their refusal to separate technology from politics, and, in the case of Donna Haraway's $(1991,2016)$ and Lucy Suchman's $(1987,2007)$ situated approaches, a methodology that also provides us with an ethics of technological practice. In light of these critical positions, what choices do we have in deploying VR and what conception of memory might we originate through our engagement with the specificity of VR and associated technologies, platforms and processes? My work has attempted to investigate that which in Shield's terms is 'almost so' $(2003,43)$, dismissed by positivism as 'non-existing abstraction.' (44). In its similarity to memory, and therefore to a notion of heritage, VR has both a contingency and agency we cannot straightforwardly ontologise or dismiss. Instead, VR might be framed as that which moves us away from binaries of 'actual-ideal'(44) and material-ideal. In that vein, Turpin's Cave began as a work of virtual creative non-fiction but transmuted into an examination of precarious territory - not just the sink holes and slippages entangled in my memories of South East London, but the precarious employment practices and contemporary delusions of choice and empathy.

Rose writes of the techno-utopianism of Zuckerberg and others in relation to VR, noting how any negative concerns about the medium were 'bracketed off in favour of a vision of VR as an agent of human advancement, human betterment and life enhancement. This type of thinking has informed discourse around VR in the third wave 
and provides a backdrop to the embrace of VR for nonfiction'(Rose, 2015). And for those who do feel connected to the plight of others is the potential to encounter another logic, that of the so-called Swayze effect:

'a surveillance logic to the illusion that one is present, invisibly looking on at people from the social world. Where CGI is involved.... and some interactivity is on offer, the participant is caught in a contradiction - feeling present, yet with no role, or capacity to intervene in or influence unfolding events - a bystander with no part to play in the experience' (Rose, 2015).

Turpin's Cave was initiated in order to investigate the contingent nature of recollection and the possibilities for digitally mediating 'lost' spatial memories and cognitive sinkholes. But it ended up as a form of VR essay on platform capitalism and its entanglement with digital technology. In this context platform capitalism is a useful 'descriptive term for the centrality that platform companies—-such as... Google.. Facebook, Alibaba, Amazon, Tencent, SoftBank, Netflix, and Flipkart- - have in the construction of the contemporary form of capitalism' (Steinberg, 2019). Hypocritically and inadvertently, what began as a work of creative non-fiction has become an unplanned memorial to the hidden heritage of Platform Capitalism, to the rise of a global Preacriate. It is the contention of this paper that insecure, temporary employment, has an ontological relationship to the VR hype-cycle, and to a disorienting virtuality, in which our lives are representationally unstable. As Virilio predicted in 1977, there is a clear connection between an implosion of digital interactivity and globalized digital labour, in which 'the emergence of a demand-based economy is causing an 'explosion' in new forms of employment, based on new technology and the absence of any work schedules or working hours' (Walls et al, 2018). 
In the tradition of Brechtian Theatre Turpin's Cave attempts to fill-in 'the abyss which separates the actors from the audience like the dead from the living' (Silverman, 2013), and to surface some of the mechanisms and ideologies of VR mediated nonfiction, however it acknowledges the unresolvable contradiction at its heart, not least of all the asymmetrical power relations embedded in its process. By exposing these contradictions, the intention is to provide a provocative counter to the empathy rhetoric so frequently invoked by non-fiction VR works. The project seeks to highlight workers and working conditions which are almost invariably invisible within such narratives.

Word count: 4200

\section{References}

Aristotle, 330 BCE, 'Poetics', Perseus.tufts [online], Available at: http://www.perseus.tufts.edu/hopper/text?doc=Perseus:text:1999.01.0056 (Accessed $31 / 08 / 18)$

Arora, Gabo, Milk, Chris, Pousman, Barry, 2015, Clouds over Sidra [360 film]

Bell, N., Langlands, B, 2003, The House of Osama bin Laden [installation], Documentation available at : http://www.langlandsandbell.com/portfolio-item/thehouse-of-osama-bin-laden-stills-2003/ Accessed 20/10/18.

Bloom, P, 2017, Against Empathy, New York, Harper Collins.

Bertrand, P., Guegan J., Robieux, L, McCall Cade, A., Zenasni, F., 2018, Learning Empathy Through Virtual Reality: Multiple Strategies for Training Empathy-Related Abilities Using Body Ownership Illusions in Embodied Virtual Reality, Frontiers in Robotics and AI, Volume 5, Available at: 
https://www.frontiersin.org/article/10.3389/frobt.2018.00026 Accessed 20/10/18.

Crowther, W, 1976, Colossal Cave Adventure, Microsoft Studios, EC Software

Consulting, Inc.

Dovey, Giddings, Grant, Kelly, Lister (2003) New Media: A Critical

Introduction, London, New York, Routledge.

Gauntlett, J., Somerville, A. 2015, In My Shoes, Dancing with myself, [360 film]

Documentation available at: http://janegauntlett.com/in-my-shoes-dancing-with-myself/

Grau. O., 2004, Virtual Art: From Illusion to Immersion, Cambridge, MA, the MIT

Press.

Gregg, Melissa (2018) Counterproductive: Time Management in the Knowledge

Economy, Durham, Duke University Press.

Halpern, Orit, 2015, 'The Trauma Machine: Demos, Immersive Technologies and the

Politics of Simulation' (in Alleys of your mind: Augmented intelligence and its traumas,

edited by Matteo Pasquinelli, 53-67 Luneburg: meson press. DOI 14619/014

Available at: https://publicityreform.github.io/findbyimage/readings/halpern.pdf

Accessed 11/03/2019.

Hansen, M. B. N., 2004, New Philosophy for New Media, Cambridge, MA, the MIT Press.

Haraway D., 1991, 'The Cyborg Manifesto', from, Simians Cyborgs and Women: The Reinvention of Nature, New York, Routledge.

Haraway, D, 2016, Staying with the Trouble, Durham, Duke University.

Hayles K. N., 1999, How We Became Post Human, Chicago and London: The University of Chicago Press.

Mestre, D. R., 2005, 'Immersion and Presence', ism.univmed[online], available at: http://www.ism.univmed.fr/mestre/projects/virtual\%20reality/Pres_2005.pdf(Accessed 
$31 / 08 / 18)$

Milk, Chris, 2015, How Virtual Reality can create the Ultimate Empathy Machine

[video] Ted Talk. Available at:

https://www.ted.com/talks/chris_milk_how_virtual_reality_can_create the_ultimate_e mpathy_machine

Accessed 11/03/2019.

O’Hagan, S. 2003. The Man Who Wasn't There, The Guardian Online \{online]

Available at: https://www.theguardian.com/artanddesign/2003/mar/30/art.artsfeatures

Accessed 20/10/18.

Pedwell, C., 2012, Economies of Empathy,[online] Sage, available at:

http://journals.sagepub.com/doi/10.1068/d22710 Accessed 20/10/18.

Plato, 360 BCE, 'Republic, ' Classics MIT [online], available at:

http://classics.mit.edu/Plato/republic.html

(Accessed 31/08/18).

Project Empathy, n.d, Project Empathy, Available at:

https://www.projectempathyvr.com/\#empathy (Accessed 31/08/18).

Rose, Mandy, 2018, 'The Immersive turn: hype and hope in the emergence of virtual reality as a nonfiction platform'. From Studies in documentary film, 2018, Vol 12, Ni 2, 132-149.

Available at: http://eprints.uwe.ac.uk/37041/ Accessed 11/03/2019.

Ryan, M-L. (2015) Narrative as Virtual Reality 2. Revisiting Immersion and

Interactivity in Literature and Electronic Media, Baltimore: John Hopkins Press.

Shields, R., 2003, The Virtual, London and New York, Routledge.

Silverman, Kaja (2013) The Threshold of the Visible World. London, Taylor \& Francis. 
Sismondo, S., 2010, An Introduction to Science and Technology Studies, Oxford, Blackwell Publishing.

Srnicek, Nick, 2016, Platform Capitalism, Cambridge, Polity Press.

Standing, G., 2011, The Precariate, the new dangerous class, London, Bloomsbury.

Steinberg, Marc, 2019, The Platform Economy, Minneapolis, University of Minnesota Press.

Suchman, Lucy (2016)' Configuring the Other: Sensing War Through Immersive Simulation', Catalyst, Vol 2, No 1. Available at:

https://catalystjournal.org/index.php/catalyst/article/view/suchman Accessed $11 / 03 / 2019$.

Suchman, Lucy, 1987, Plans and Situated Actions: The Problem of Human-machine Communication, New York: Cambridge University Press.

Suchman, Lucy, 2007, Human-Machine Reconfigurations: Plans and Situated Actions, New York,Cambridge University Press.

Taylor, Matthew, 2018, 'Paying for Flexibility: Should workers on zero-hours contracts receive a higher minimum wage?' $R S A$.

UKRI, n.d., 'Audience of the future', UK Research and Innovation [online] Available here: https://www.ukri.org/innovation/industrial-strategy-challenge-fund/audience-ofthe-future/

Virilio, P., 1977, Open Sky, London, Verso.

Wall, Lesley, Revie, Matthew, Bedford, Tim. (2018) Risk, Reliability and Safety: Innovating Theory and Practice, London, Taylor \& Francis.

Yu, D., 2008, Spelunky, Mossmouth, LLC, Microsoft Studios (X360). 
Zahlten, Alexander, 2017, The End of Japanese Cinema: Industrial Genres, National Times, and Media Ecologies, Durham, Duke University. 